\title{
ПОРОЖДЕНИЕ НОВОГО ЗНАНИЯ ДЛЯ СОЗДАНИЯ БАЗ ЗНАНИЙ ИНТЕЛЛЕКТУАЛЬНЫХ СИСТЕМ
}

\author{
Б. Е. Одинцов \\ Финансовый университет при Правительстве Российской Федерации
}

Поступила в редакцию 05.02.2019 г.

\begin{abstract}
Аннотация. Уровень интеллектуальности информационной системы во многом определяется качеством ее базы знаний, одной из форм представления которых являются когнитивные модели. Когнитивное моделирование, пытаясь ответить на вопрос: какие процессы происходят в сознании человека при работе с информацией, является мощным инструментом воспроизведения связей в реальном мире. Для этого интенсивно развиваются методы для визуального представления процессов, позволяющих отобразить латентные или плохо идентифицируемые характеристики моделируемых объектов. В статье предлагается в качестве одного из таких инструментов использовать когнитивные карты метафор, часто необходимых человеку для идентификации неявных свойств реальных объектов. Рассматривается пример, в котором показано каким образом, меняется содержание когнитивной карты, в результате преобразования обычной словообразовательной модели в модель метафоры. Ключевые слова: интеллектуальные системы, базы знаний, порождение новых знаний, метафора, когнитивная карта, когнитивное представление метафоры, интеграция знаний. Annotation. The level of intelligence information system largely depends on the quality of its knowledge base, one of the forms of representation which are cognitive models. Cognitive modeling, trying to answer the question: what processes occur in human consciousness when dealing with information is a powerful tool for playlist links in the real world for this intensively develop methods to visualize processes to enable display latent or poorly identifiable characteristics of the simulated objects. In article is proposed as one such tool use cognitive maps of metaphors, often required a person to identify implicit properties of real objects. An example that shows how the content is changing cognitive maps, resulting from the transformation of the usual word formation models in model of metaphor.

Keywords: intelligent systems, knowledge bases, generation of new knowledge, metaphor, cognitive map, cognitive view of metaphor, integration of knowledge.
\end{abstract}

\section{ВВЕДЕНИЕ}

Семантическая мощность когнитивных моделей реанимировала веру в создание глобальных, региональных, локальных, городских и других моделей, отражающих взаимосвязанные экономические, политические, экологические и др. процессы. Благодаря им открылись новые перспективы в определении путей развития как общества в целом, так и отдельных сфер его деятельности, а затем - и построения всеобщей (глобальной) модели социально-экономического развития современной цивилизации. Постепенно укрепля-

() Одинцов Б. Е., 2019 ется вера в адекватность применения слабо структурированной или вовсе не структурированной, интуитивной, плохо вербализованной и неформализованной информации, используемой для представления причинно-следственных связей экономического и социального характера.

Поэтому сегодня, когда быстрыми темпами развивается искусственный интеллект, становится актуальным дальнейшее развитие действенных инструментов, предназначенных для генерации, приобретения, извлечения и порождения знаний, являющихся основой для функционирования всякой интеллектуальной системы. Далее все перечисленные термины будут рассматриваться в ка- 


\section{Б. Е. Одинцов}

честве синонимов единого класса понятий, обозначаемого словосочетанием порождение знаний.

При всей важности процесса порождения новых знаний методов для их реализации пока недостаточно. В работе [7] эти методы разделены на два класса: коммуникативные и текстологические: первые предполагают привлечение экспертов - носителей знаний, а вторые ориентируют на работу с документами (методиками, инструкциями) и специальной литературой (текстами, статьями, монографиями). Странным образом в данную классификацию не вошли автоматизированные, то есть программные методы, которые можно разделить на три подкласса: DM (Data Mining) - составляющие технологию интеллектуального анализа данных, ML (Machine Learning) - использующие машинное обучение и логический (прямой и обратный вывод), а также нечеткого (Fuzzy Logic) вывода новых знаний на основании старых. Далее будем анализировать текстологический метод, как наименее развитый. Здесь же отметим, что настоящая статья является продолжением работ $[6,8]$, где заложены основы машинного распознавания смысла запроса с помощью ассоциативных и интуитивных знаний.

\section{ТЕОРЕТИЧЕСКАЯ ЧАСТЬ}

Выбор пути порождения нового знания на базе обработки текстов сегодня достаточно проблематичен, так как Дж. Лакофф и М. Джонсон, проанализировав особенности семантики языка, обнаружили, что «большая часть понятийной структуры естественного языка по своей сути метафорична» [1]. Данное обстоятельство является причиной обострения вопроса о путях развития естественных и гуманитарных наук, который формулируется следующим образом: Развиваются ли науки в направлении от обычных моделей к метафорам, или от метафор к обычным моделям? В настоящей статье нет ответа на данный вопрос, однако уместно привести следующий ряд: реальность-модель-метафора-миф-сказка, демонстрирующий снижение уровня адекватности форм представле- ния знаний человеком о действительности. Приведен он для того, чтобы подчеркнуть важность определения черты, после которой человек оказывается в мире мифов (сказок), знания о котором малопродуктивны в реальной сфере управления. Поэтому остановимся на метафорах по двум причинам:

- за счет образности языка и художественной выразительности метафоры обнажают латентные (неявные) знания, которые впоследствии позволяют рассмотреть ситуацию под новым углом зрения и, за счет этого, появляется возможность корректировки уже имеющихся моделей;

- продвижение же от метафор к мифам и далее требует специальных дополнительных исследований, касающихся способов специальной очистки столь необычных, с точки зрения формальной обработки новых знаний.

Вопрос о путях подлинного развития наук, а значит и порождаемых ими моделей, не праздный, так как в состав научного знания все чаще включаются специальные стилистические приемы, направленные на поиск истины. В научное знание все чаще включаются элементы, сближающие творческие практики с практиками науки, эстетику искусства с эстетикой научного мышления.

Известен скептицизм, относительно пути развития наук от метафор к моделям, базирующийся на том, что мышление подчиняется лингвистическим законам, а значит объективно не может отражать истину. И он вполне понятен. Но следует также учесть, что кроме аналитических свойств языка, существует еще и образность, а также способность к иносказанию. Без метафор эти свойства не позволят приблизиться к ответу на вопрос: «Каким образом происходит прирост нового знания в обществе за счет текстуальной обработки?».

Как правило, метафора (от греческого metaphora - перенос) применяется для указания непрямого значения за счет иносказания [2, с. 296], Под метафорой понимается следующее: это троп, слова, которого обозначают некоторый класс предметов, явлений и тому подобное, для характеристики или наименования другого класса объектов, аналогичного данному в каком-либо отношении [3]. Троп 
(от др.-греч. тро́тос - оборот) - это риторическая фигура, слово или выражение, используемое в переносном значении с целью усилить образность языка или художественную выразительность речи. Как обозначаемый, так и обозначающий в тропе объекты могут иметь сходство предметов по форме, цвету, размерам, ощущениям и т. д. или не иметь их вовсе. Иными словами слова в метафоре обозначают некоторый класс объектов, явлений или признаков, используемых для представления или номинации другого (сходного, мало сходного или вовсе несходного) класса объектов.

В истории гуманитарных наук трактовка данного понятия изменялась от одной крайности к другой: от «метафорична сама мысль» или это «форма научной мысли», до его противоположного понимания - это «категориальная ошибка» или «семантическая концептуальная аномалия».

Далее будем считать, что мысли не всегда, но в какой-то мере (возможно большей) метафоричны, что неплохо осознается человеком, так как метафора - это не просто языковой инструмент, но и способ общения в повседневной трудовой и бытовой деятельности. Человеку свойственно думать об одной сфере в терминах другой и для этого ему не требуются доказательства правильности его мыслей. Например, на предприятии мало кто осознает, что такие словосочетания как «инновационный климат», «атмосфера предприятия» - есть метафоры, выполняющие ту же функцию, что и обычная буквальная словесная модель, но только более емкая по содержанию.

Так как возможно буквальное и метафоричное использование слов и словосочетаний, будем полагать, что создание модели метафоры, рассматриваемой в качестве необычной словесной структуры, возможно. Последняя, в случае надобности, впоследствии может быть преобразована в обычную словесную модель. Эти модели несут различные по емкости семантику: если метафоричная может служить источником нового знания, то вторая нет. Причиной этого является то, что существует отличие между буквальными моделями и метафорами за счет разницы в отражении количества объектов и их связей, и это главное, с точки зрения поиска, и выявления чего-то нового, которое должно быть выведено из «тени» и представлено явно в модели. Метафоричное выражение характеристик объекта богаче, по сравнению с буквальной словесной моделью, и потому, может рассматриваться в качестве первичного этапа обычной модельной формализации.

Для доказательства того, что метафора богаче обычной словесной модели воспользуемся аналогией, приравняв ее к стихотворному искусству, так как и то, и другое - это сложно изложенный смысл. Это позволяет обратиться к трудам выдающегося семиотика Ю. М. Лотмана, где он анализирует семантическую емкость прозы, а таковой является обычная словесная модель (например, фраза из уголовного кодекса), которая должна быть однозначной, и стиха, содержание которого, как правило, неоднозначно. Объясняя структуру сложно образованного текста, он указывает на то, что слова в стихотворении связываются не только сложной системой соотношений, но и, как правило, противопоставлений, невозможных в обычной языковой конструкции. Тем самым придается всей конструкции совершенно новая семантическая нагрузка. Слова, предложения и высказывания, в грамматической структуре, находящиеся в разных, лишённых черт сходства, и, следовательно, несопоставимых позициях в стихотворной структуре, оказываются и сопоставимыми, и противопоставимыми, и вполне приемлемыми. Именно последнее является в них новым знанием. В своей работе [4] Ю. М. Лотман подчеркивает: «...это раскрывает в них неожиданное, вне стиха невозможное, новое семантическое содержание» [c. 88] Из этого следует, что метафора является источником нового взгляда, нового понимания, а значит - и нового знания. Остается только найти способ его выявления и представления для практического использования. Рассмотрим его.

Метафоричное описание, хоть и страдает «категориальной ошибкой» или «семантической концептуальной аномалией», но все же, как уже показано, отражает новое знание за 


\section{Б. Е. Одинцов}

счет семантической двойственности (двуплановости), обращающейся к буквальному и, одновременно, к образному значению слов или предложений. Но ведь любое описание предметной области всегда более и менее метафорично, так как требуется подводить его под различные понятия, замещая ими реальные процессы и объекты. Тогда в чем разница между метафорой и буквальной словесной моделью?

Нам представляется, что разницу нужно искать в практической плоскости: метафоры формируют, приводят в действие (провоцируют) и направляют человеческое мышление на отражение нового, латентного знания, находящегося в метафоре изначально. По существу, это способ идентификации ненаблюдаемых свойств объектов и процессов, позволяющий акцентировать внимание на малоизвестном и малопонятном. Удивительным образом метафоры используют в качестве инструмента объяснения того, что является малоизвестным, за счет более знакомого или лучше известного и, потому понятного. Происходит объяснение одних объектов познания через механизмы познания других. Что касается обычных словесных моделей, то в отличие от метафор, получить новое знание с их помощью можно лишь после их формальной обработки программными или другими способами, применяемыми в практике управления (например, прямой или обратный четкий или нечеткий логический вывод).

С целью совершенствования системы управления организациями (предприятиями) в работе [5] предлагается посмотреть на них под иным углом зрения, проанализировав распространенные типовые метафоры. Перечень таковых зависит от стоящих перед руководством целей. Как считает автор данной работы, «Иногда достаточно понять с какой метафорой работает руководитель, чтобы увидеть причины неудач в изменениях» [c. 472]. Автор выделяет следующие, на его взгляд распространенные на предприятии метафоры: машина, организм, мозг, культура, политическая система, душевная тюрьма. Он объясняет такие метафоры как организм и мозг тем, что они отражают биологический и когнитивный аспекты предприятия, метафоры производственная культура и политическая система - разнообразие социальных аспектов. В наибольшем же контрасте с реальной действительностью находятся метафоры организации как машины и живой системьы.

Перед нами метафоры в виде слов или их сочетаний, которые буквально не применимы в управлении, но используются в ежедневной практике для того, чтобы оттенить или показать их авторами сходство чего-либо с чем-то другим, подспудным, неявным, глубинным. Каждая из них представляет два разных метафорических выражения - прямое и переносное, то есть подразумеваемое.

\section{РЕЗУЛЬТАТЫ ИССЛЕДОВАНИЙ}

Когнитивный (познавательный) взгляд на метафору мы связываем с потребностью поиска заключенных в ней латентных (глубинных) знаний и, поэтому, она рассматривается в качестве способа мышления, осознания и изучения объектов как части мира. Для представления когнитивной структуры метафорической модели и ее языковых реализаций, как правило, используются фреймы, способные отражать стереотипные ситуации. Фреймы изображаются в виде сети слотов ячеек, заполняемых информацией. Однако в данном случае, с практической точки зрения, фреймовые структуры малоприменимы, так как не обладают развитым арсеналом изобразительных средств. Поэтому обратимся к когнитивным картам, семантическая мощность которых неизмеримо выше. На рис. 1 приведены две когнитивные карты: а) обычная буквальная словообразовательная модель, отражающая лежащие на поверхности причинно-следственные связи межу известными понятиями, и б) метафорическая модель, отражающая (провоцирующая) иной взгляд на ту же ситуацию.

Связь между факторами в когнитивной карте характеризуется не только направлением динамики объекта (рост, снижение), но и интенсивностью их влияния, выражаемой либо количественно, либо качественно с помощью лингвистических переменных. 
Порождение нового знания для создания баз знаний интеллектуальных систем

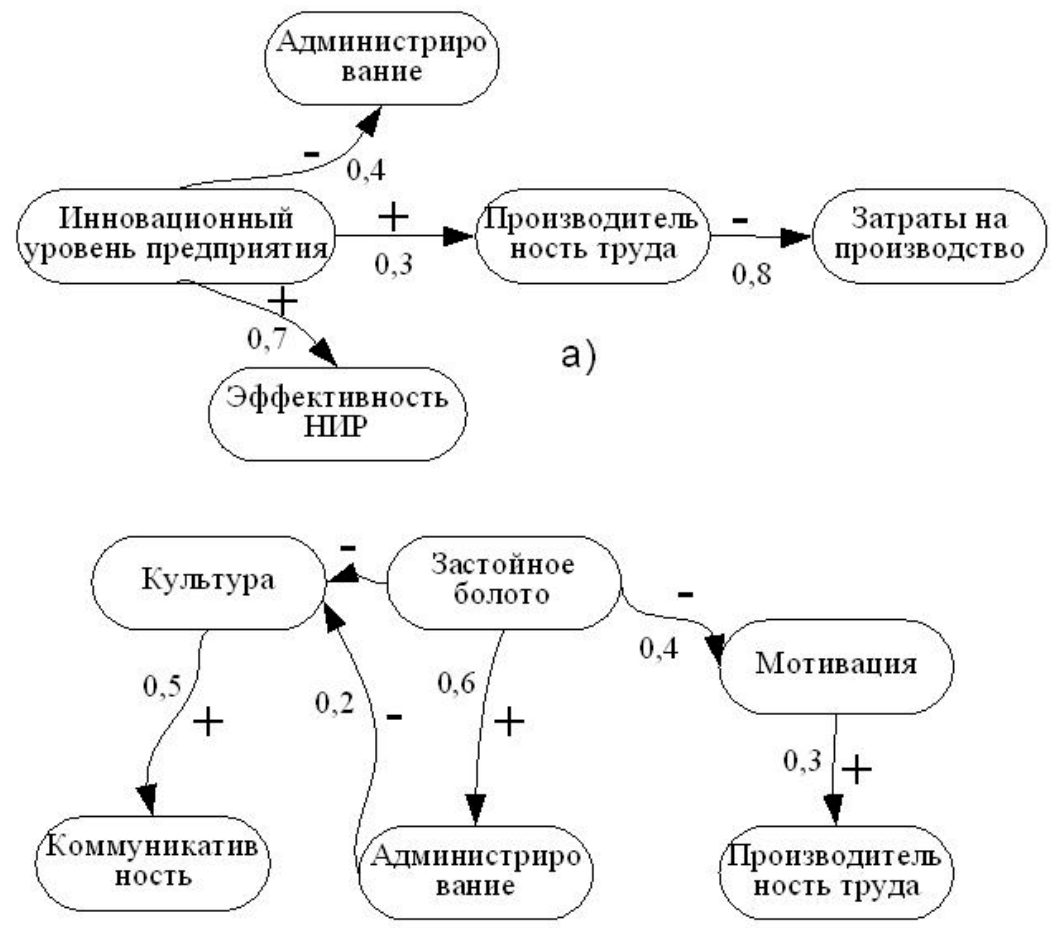

б)

Рис. 1. Буквальная словообразовательная модель а) и метаборичная модель б)

Представлять когнитивную карту удобно с помощью ориентированного графа, ребра которого имеют веса, как правило, в диапазоне от -1 до 1 со знаками «+» или «-». Знак «+» обозначает положительную связь, знак «-» - отрицательную. При положительной связи рост узла-причины приводит к росту (снижению) узла-следствия, а при отрицательной связи рост узла-причины приводит к уменьшению (росту) узла-следствия. Более детально об элементах когнитивной карты речь идет в работе [6].

Согласно приведенному ранее определению метафоры и уже введенной терминологии, обозначаемым классом на рис. 1 будет служить понятие инновационный уровень предприятия, а обозначающим - застойное болото. Здесь наблюдается сходство не по цвету, размерам, и т. д., а скорее - по форме и ощущениям. Однако без особого труда можно обнаружить вполне логичную связь между факторами в обоих вариантах. В буквальной словесной модели отражены следующие знания: повышение инновационного уровня предприятия положительно влияет на производительность труда и эбфективность НИР, что в свою очередь также ведет к снижению затрат на производство.
Совсем иная картина наблюдается в метафорической модели. Обозначающим в ней фактором служит застойное болото, что ассоциируется, с одной стороны, с его отрицательным влиянием на уровень культуры и мотивации к труду, а с другой - увеличением административного давления, и, как следствие, снижением уровня коммуникативности членов общества и производительности труда.

По вполне объяснимым причинам возникает потребность в слиянии старого и нового знания в единую когнитивную модель. Для этого можно воспользоваться двумя способами: а) установить новые связи между ключевыми факторами той и иной модели, и б) ввести специальный дополнительный связующий фактор. Затем, в любом случае, необходимо ликвидировать дублируемые факторы. Воспользуемся первым и получим новую (см. рис. 2), уже обогащенную метафоричными характеристиками когнитивную карту. Как видим, самой метафоры в ней нет, но есть новые характеристики инновационного предприятия: культура, мотивация, коммуникативность, администрирование. 


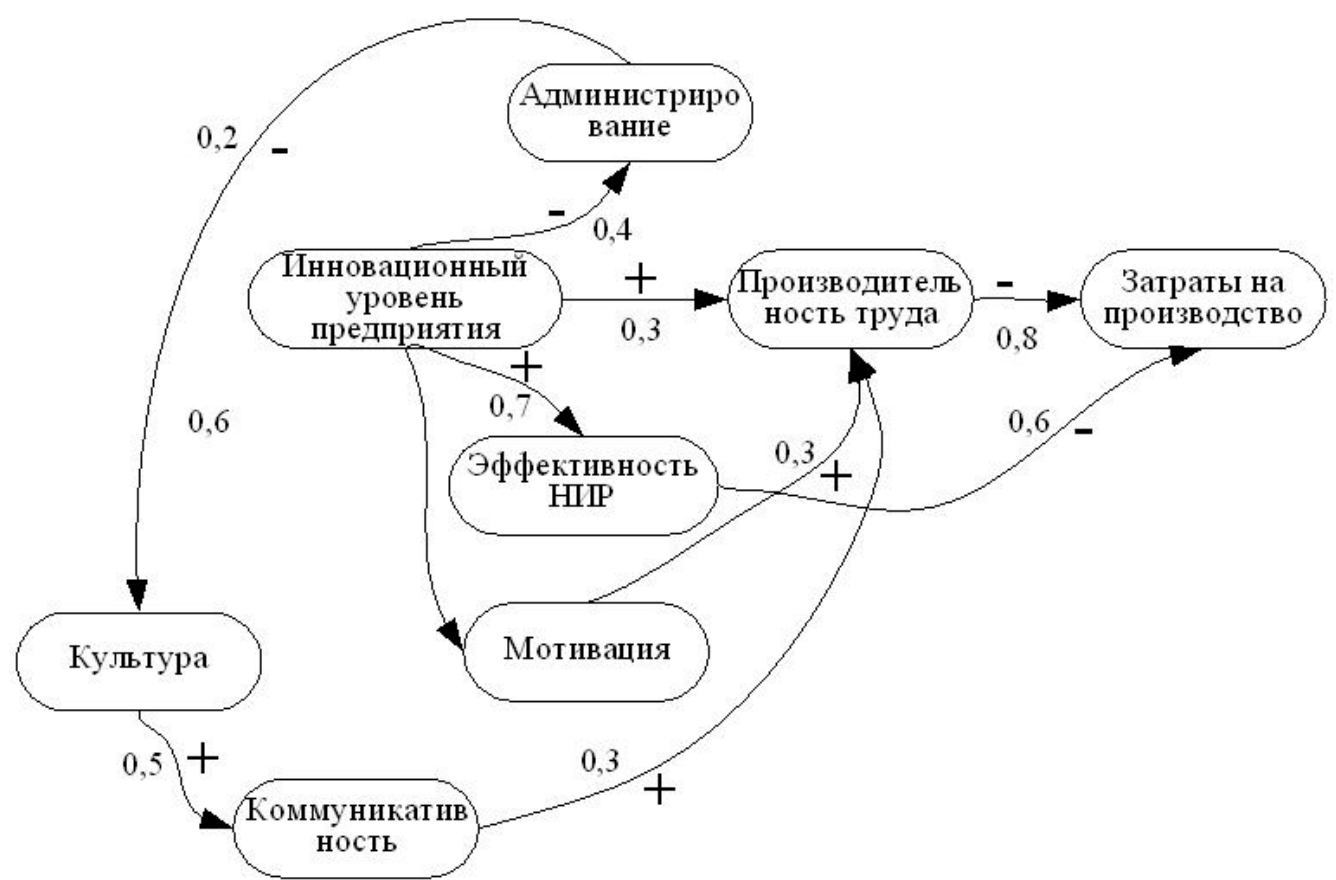

Рис. 2. Когнитивная карта, обогащенная новыми факторами и связями

\section{ЗАКЛЮЧЕНИЕ}

Таким образом, продемонстрированы потенции метафоры, помогающие осуществлять познавательные процессы. С ее помощью получено более углубленное представление о мире (в данном случае предприятии), используемое для создания новой, более адекватной модели базы знаний. Метафорический взгляд не только на предприятие, но и на процессы вне его, можно рассматривать как мощный инструмент выполнения этапа, предшествующего получению обычной словесной модели, что существенно повысит эффективность когнитивных моделей регионального, государственного, а за тем и глобального уровней.

\section{СПИСОК ЛИТЕРАТУРЫ}

1. Лакофб Дж., Джонсон М. Метафоры, которыми мы живём. М. : Едиториал УРСС, 2004. - 256 c.

2. Лингвистический Энциклопедический словарь 1990 года. Главный редактор В. Н. Ярцева. - М. : «Советская энциклопедия». 1990. - 685 c.

3. Понятия «метафора» и «метафорическая модель». [Электронный ресурс]. Режим доступа: https://studwood.ru/548630/ literatura/teoreticheskie_aspekty_ issledovaniya_metaforicheskih_modeley_roli_ publitsisticheskih_tekstah.

4. М. Лотман и тартуско-московская школа. - М. : Гнозис, 1994. - 560 с.

5. Морган Гарет. Образы организации / Гэрет Морган; [пер. с англ. - И. Матвеева, Р. Самуненков]. - М. : Манн, Иванов и Фербер, 2008. - 501 c.

6. Одинцов Б. Е. Когнитивные древовидные структуры в управлении слабо формализованными социально-экономическими процессами // Информатизация образования и науки. - 2017. - № 2. - С. 46-57.

7. Гаврилова Т. А., Муромиев Д. И. Интеллектуальные технологии в менеджменте: инструменты и системы: Учеб. пособие. Высшая школа менеджмента СПбГУ. - СПб. : Изд-во «Высшая школа менеджмента»; Издат. дом С.-Петерб. гос. университета. - 2008. - 488 с.

8. Романов Б. Е., Одинцов Б. Е. Интеллектуализация сетевых систем поиска экономической информации: Монография. - М. : Вузовский учебник: ИНФРА-М, 2010. - 144 с. 
Порождение нового знания для создания баз знаний интеллектуальных систем

Одинцов Борис Ефимович - доктор экономических наук, профессор департамента анализа данных, принятия решений и финансовых технологий Финансового университета при Правительстве Российской Федерации. E-mail: Odintsov45@list.ru
Odintsov Boris E. - Doctor of Economics Sciences, Professor of the Department of data analysis, decision-making and financial technologies Financial University under the Government of the Russian Federation.

E-mail: Odintsov45@list.ru 